\title{
O Pibid como política pública de formação docente: discutindo resultados exitosos
}

Antônia Sueli da Silva Gomes Temóteo*

Cláudia Alves da Silva**

* Professora dos Cursos de Letras e Pedagogia da Universidade do Estado do Rio Grande do Norte (UFRN). Doutoranda em Linguística Aplicada da Universidade do Vale do Rio dos Sinos suelisilva.17@hotmail.com

**Mestranda em

Educação pela UFRN claudiaposeduc14@bol.com.br
Resumo: A formação docente constitui-se de várias etapas, sendo a graduação a primeira delas. Nesta fase, o graduando começa a constituir-se docente por meio das teorias presentes nas disciplinas e da prática via estágios. Ainda assim, são perceptíveis as lacunas na sua formação, sendo indispensável vivenciar outras experiências. Estas, por sua vez, estão sendo propiciadas pelo Pibid enquanto programa formativo, por meio da unidade teoria/prática, concebida no intercâmbio universidade/escola pública. Respaldado teoricamente por autores como Gauthier (2006) e Tardif (2007), entre outros, este trabalho objetiva apresentar relatos sobre como os pibidianos vivenciaram a relação teoria/prática no programa e as contribuições desta para sua formação.

Palavras-chave: Formação docente. Pibid. Teoria/prática. 
O Programa Institucional de Bolsas de Iniciação à Docência - Pibid foi lançado pela Coordenação de Aperfeiçoamento de Pessoal de Nível Superior - Capes no ano de 2007 alicerçado em princípios que tomam como base a formação docente, visando uma formação centrada no diálogo entre universidade/ escola pública, primando sempre pela relação teoria/prática.

A priori, surgiu para atender apenas as áreas específicas, como física, química, biologia e matemática para o ensino médio, tendo em vista a significativa carência de professores para lecionarem nessas disciplinas. Pouco tempo depois, com a implantação de novas políticas públicas para valorização do magistério e a crescente demanda, aliados aos bons resultados já alcançados pelo programa, no ano de 2009 o Pibid foi expandido, passando a atender toda a educação básica. De acordo com dados do Relatório de Gestão, o programa está presente hoje por todo o Brasil, sendo o Nordeste a região que apresenta maior número de bolsistas e de Instituições de Educação Superior - IES participantes.

Visando alcançar resultados positivos no que se refere à formação docente em nível superior, o Pibid traçou vários objetivos a serem alcançados, dentre eles, o que trata sobre "inserir os licenciandos no cotidiano de escolas [...] proporcionando-lhes oportunidades de criação e participação em experiências metodológicas, tecnológicas e práticas docentes de caráter inovador e interdisciplinar" (BRASIL, 2013, p. 6). Tal objetivo nos fez voltar os olhares para investigar: a inserção dos licenciandos no espaço escolar por maior período de tempo é capaz de propiciar uma formação em que a relação teoria/prática se encontra mais latente? Após pesquisas desenvolvidas, foi possivel encontrar respostas afirmativas que deram margem à produção deste trabalho, e ainda poder afirmar que o Pibid pode ser considerado uma política de formação docente exitosa.

Num primeiro momento, o texto se encaminha para discutir sobre as necessidades de uma formação docente calcada na relação teoria/prática e na dialogia universidade/escola básica. Num segundo momento, analisaremos os resultados encontrados por meio das pesquisas junto aos bolsistas graduandos vinculados ao programa.

Considerando a pertinência da discussão ora apresentada, espera-se que este trabalho contribua para o aprimoramento da formação inicial de professores, a partir das atividades que se desenvolvem no interior das instâncias 
formativas, considerando, primordialmente, a relação universidade/escola, a unidade entre teoria e prática e as reflexões inerentes a esse contexto.

\section{AS EXIGÊNCIAS DA FORMAÇÃO DOCENTE PARA A ATUALIDADE}

As Diretrizes Curriculares para a Formação Inicial de Professores da Educação Básica dispõem que "a internacionalização da economia confronta o Brasil com os problemas da competitividade para a qual a existência de recursos humanos qualificados é condição indispensável” (BRASIL, 2000, p. 17), isto é, todos os setores do país necessitam de profissionais que estejam preparados para atender às mudanças ocorridas dentro da sociedade que ora se apresenta.

No âmbito educacional, essas exigências são ainda mais latentes, pois, segundo as Diretrizes Curriculares, "no mundo contemporâneo, o papel do professor está sendo questionado e redefinido de diversas maneiras" (BRASIL, 2000, p. 5). Muito embora as transformações nos currículos de formação de professores ofertados nas licenciaturas tenham ocorrido de forma significativa, as Diretrizes ainda apontam para a não preparação dos professores para atenderem a essas exigências, pois dizem ser "imprescindível rever os modelos de formação" a fim de que visem em linhas gerais:

Fortalecer e aprimorar a capacidade acadêmica e profissional dos docentes formadores; Articular a formação com as demandas da realidade escolar na sociedade contemporânea; Articular a formação com as mudanças em curso na organização pedagógica e curricular da educação básica brasileira, preparando os professores para serem agentes dessas mudanças

Para que essas mudanças saiam da retórica e se convertam em realidade, é preciso que as secretarias de educação, juntamente com as universidades e as instituições de formação de professores, adotem tais normas, objetivos ou atitudes, mas que tenham como visão a de que:

Melhorar a formação docente implica instaurar e fortalecer processos de mudança no interior das instituições formadoras, respondendo aos entraves e aos desafios apontados. Para isso, não bastam mudanças superficiais. Faz-se necessária uma revisão profunda dos diferentes aspectos que interferem na formação inicial de professores, tais como: a organização institucional, a definição e estruturação dos conteúdos para que respondam às necessidades da atuação do professor, os processos formativos que envolvem aprendizagem e desenvolvimento das competências do professor, a vinculação entre as escolas de formação inicial e os sistemas de ensino (BRASIL, 2000, p. 12). 
Mudanças como as propostas acima são de extrema necessidade e merecem ser priorizadas por se tratar da formação de base, pois, como dispõem as Diretrizes, “a formação inicial como preparação profissional tem papel crucial para possibilitar que os professores se apropriem de determinados conhecimentos e possam experimentar em seu próprio processo de aprendizagem" (BRASIL, 2000, p. 13). Entretanto, a formação inicial para o docente deve ir mais além, por considerar-se que “A formação de um profissional de educação tem que estimulá-lo a aprender o tempo todo, a pesquisar, a investir na própria formação e a usar sua inteligência, criatividade, sensibilidade e capacidade de interagir com outras pessoas" (BRASIL, 2000, p. 13).

No anseio de preparar futuros professores para o exercício da docência, não importa em que nível de escolarização eles venham a atuar, já que o processo de formação inicial para os profissionais da educação é ofertado em mais de uma modalidade e em diversos espaços. E sendo a universidade um desses espaços de construção da formação inicial, esta deve ser a responsável por fornecer o embasamento necessário para a construção do sujeito que vise ser um professor capaz de realizar seu trabalho e nele enfrentar diversos tipos de tarefas e problemas. Imbernón (2002, p. 60) aponta que a formação inicial deve:

Dotar o futuro professor ou professora de uma bagagem sólida nos âmbitos científico, cultural, contextual, psicopedagógico e pessoal deve capacitá-lo a assumir a tarefa educativa em toda a sua complexidade, atuando reflexivamente com a flexibilidade e o rigor necessários.

Essa complexidade à qual Imbernón se refere tem algo em comum com a diferença que cada vez mais ganha as salas de aula das escolas públicas, situação esta que se encontra bem delineada nas palavras de Romanowski (2007, p. 117) quando ela diz que:

A sala de aula é um ambiente de diversidade, uma vez que abriga um universo heterogêneo, plural e em movimento constante, em que cada aluno é singular, com uma identidade originada de seu grupo social, estabelecida por valores, crenças, hábitos, saberes, padrões de condutas, trajetórias peculiares e possibilidades cognitivas diversas em relação à aprendizagem.

Aos docentes que irão atuar nesse novo cenário educacional, as Diretrizes traçaram como sendo exigências colocadas ao papel dos profissionais docentes as seguintes:

Orientar e mediar o ensino para a aprendizagem dos alunos; responsabilizar-se pelo sucesso da aprendizagem dos alunos; assumir e saber lidar com a diversidade existente entre os alunos; incentivar atividades de enriquecimento curricular; elaborar e executar projetos para desenvolver conteúdos curriculares; utilizar novas metodologias, estratégias e materiais de apoio; desenvolver hábitos de colaboração e trabalho em equipe (BRASIL, 2000, p. 5). 
Para que esses profissionais possam estar preparados para atender à nova demanda educacional, faz-se necessário que na formação inicial se construam saberes que subsidiem sua profissão. Porém, os cursos de formação inicial não oferecem “um ir e vir da teoria à prática e da prática à teoria” (CARVALHO, 2005, p. 76) com naturalidade, ou seja, os professores em formação não têm nessa troca um processo comum à formação.

Aos graduandos comumente são ofertados apenas contatos isolados durante pequenos espaços de tempo chamados de estágios supervisionados, em que se vive apenas a docência e não a escola como um todo, vivência esta destacada como sendo um momento indispensável e "decisivo para esses professores estarem constantemente redimensionando seus saberes de base, a fim de poderem ensinar com mais segurança” (CARVALHO, 2005, p. 76).

Então, o Pibid, ao inserir os bolsistas durante certo período de tempo no espaço das escolas públicas, propicia a eles vivências e construções de aprendizados por meio da relação construída pelo programa entre a universidade e a escola; situação, portanto, possível geradora de uma troca significativa entre esses dois espaços e entre teoria e prática, em que o graduando possa desenvolver sua formação de maneira ampla e bem alicerçada nas ações reais que a escola oferece.

É sobre essas vivências e os aprendizados que o Pibid tem proporcionado aos bolsistas, por meio de seus contatos com a escola, que o subtópico seguinte discorre.

\section{A FORMAÇÃO DOCENTE CONSTITUÍDA NA RELAÇÃO TEORIA/PRÁTICA VIA ESPAÇOS FORMADORES UNIVERSIDADE/ESCOLA PÚBLICA}

A formação docente, o produzir a profissão, o tornar-se professor e, entre outros, a construção dos saberes são temáticas que vêm ganhando espaço em meio aos frequentes debates nas academias. Como aponta Gauthier (2006, p. 28), é "pertinente conceber o ensino como a mobilização de vários saberes”. Desse modo, é cabível indagar: o que se entende por saberes? Que saberes são esses tão indispensáveis ao ofício da docência?

Para Gauthier, os saberes docentes se configuram em seis: o saber disciplinar, o saber curricular, o saber das ciências da educação, o saber da tradição pedagógica, o saber experiencial e o saber da ação pedagógica. Para o autor, "O saber disciplinar [...] se refere aos saberes produzidos pelos pesquisadores e cientistas nas diversas disciplinas científicas" e que "o professor não produz" 
esse saber "mas, para ensinar, extrai o saber produzido por esses pesquisadores" (GAUTHIER, 2006, p. 29). Sobre o saber curricular, o autor diz que são "saberes produzidos pelas ciências" e transformados pelas escolas "num corpus que será ensinado nos programas escolares" (GAUTHIER, 2006, p. 30).

O saber da ciência da educação, na visão do autor, diz respeito aos saberes:

relativos ao sistema escolar [...] um conselho escolar, um sindicato, uma carga horária [...] uma idéia sobre a evolução de sua profissão [...] noções sobre o desenvolvimento da criança, as classes sociais, os estereótipos, a violência entre os jovens, a diversidade, etc. [...] um conjunto de saberes a respeito da escola que é desconhecido pela maioria dos cidadãos comuns e pelos membros das outras profissões [...] mas serve de pano de fundo tanto para ele quanto para os membros de sua categoria [...] esse tipo de saber permeia a maneira de o professor existir profissionalmente (GAUTHIER, 2006, p. 31)

O saber da tradição pedagógica é tratado por Gauthier como sendo "o praticar [...] o ensino simultâneo, dirigindo-se a todos os alunos ao mesmo tempo" e que se propaga por meio do "saber dar aulas" nessa perspectiva e "representação da escola que o determina antes mesmo de ter feito um curso de formação de professores". Já o saber experiencial tem a ver com o "aprender através de suas próprias experiências [...] viver um momento particular [...] diferente de tudo o que se encontra habitualmente registrado" e, por último, o saber da ação pedagógica, que é "o saber experiencial dos professores a partir do momento em que se torna público [...] testado através das pesquisas"; este, por sua vez, é destacado como sendo "o mais necessário à profissionalização do ensino [...] visto que os saberes da ação pedagógica constituem um dos fundamentos da identidade profissional do professor" (GAUTHIER, 2006, p. 32-34).

Tardif também debate sobre esses mesmos saberes dizendo que são da formação profissional, disciplinares, curriculares e experienciais. Na sua visão, são saberes da formação profissional "o conjunto de saberes transmitidos pelas instituições de formação de professores". Os saberes disciplinares "correspondem aos diversos campos do conhecimento, aos saberes de que dispõe a nossa sociedade, tais como se encontram hoje integrados nas universidades, sob a forma de disciplinas, no interior de faculdades e de cursos distintos" e curriculares quando estiverem relacionados "aos discursos, objetivos, conteúdos e métodos a partir dos quais a instituição escolar categoriza e apresenta os saberes sociais por ela definidos e selecionados como modelos de cultura erudita e de formação para a cultura erudita” e também porque "apresentam-se concretamente sob a forma de programas escolares (objetivos, conteúdos, métodos) que os professores devem aprender como aplicá-los" (TARDIF, 2007, p. 36-38). 
Para a autora, existem também os saberes da experiência que são:

O conjunto de saberes atualizados, adquiridos e necessários no âmbito da prática da profissão docente e que não provêm das instituições de formação nem dos currículos [...] e [...] formam um conjunto de representações a partir das quais os professores orientam sua profissão e sua prática cotidiana em todas as suas dimensões (TARDIF, 2007, p. 38).

Corroborando com os pensamentos dos autores mencionados, Pimenta (2008) também traz discussões acerca dos saberes. Para ela, os saberes da docência são os da experiência, do conhecimento e os pedagógicos. Sobre os saberes da experiência, a autora diz que são aqueles trazidos da vivência enquanto aluno, dos vários professores de sua vida escolar. Os saberes do conhecimento, ela trata como sendo os saberes inerentes às disciplinas e conteúdos ministrados nas escolas. Por último, os saberes pedagógicos como sendo o saber ensinar e o saber-fazer.

Todos esses saberes juntos se encaminham para a formalização da profissão docente. No entanto, para que essa formalização ocorra, faz-se necessário que o futuro professor passe por experiências que the propiciem vincular a "resolução de problemas reais com momentos de ação e momentos de constituição de competências novas", como bem afirmam ${ }^{1}$ Porlán e Rivero (1998 apud ENRICONE, 2008, p. 29).

O ofício de professor não se faz apenas com os saberes disciplinares vivenciados nas academias, mas sim de vários outros saberes construídos ao longo da formação, os quais Gauthier (2006) afirma serem essenciais à profissão. Entre esses saberes, estão os produzidos no lócus de trabalho, por meio do contato com a escola e com tudo o que nela está constituído. Como referenciado no item anterior, esse contato oferecido somente nos períodos de estágio deixa uma lacuna perceptível no processo formativo desses licenciandos.

No Pibid, essa experiência é vivenciada de forma mais abrangente e prolongada, proporcionando ao bolsista um contato mais próximo da realidade escolar, explicitando num dos objetivos traçados a promoção da integração universidade/escola, sendo que essa integração deve ocorrer "através da partilha de experiências formativas que possibilitem um processo mútuo de aprendizagem e construção de novos conhecimentos", como apontado em Brasil (2011).

Por meio dessas vivências, o Pibid pretende proporcionar ao graduando a oportunidade de refletir sobre as atividades desenvolvidas em sala, discutir 
os pontos que deram e os que não deram certo, encaminhar meios de melhorar os pontos que não se saíram bem e ainda avaliar a aplicação das ideias pensadas em conjunto com os professores da sala a fim de melhorar o que não estava satisfatório. Com isso, o bolsista aprenderá a ser um professor reflexivo e pesquisador de sua prática, exigências essas feitas aos educadores desse novo século.

Em suma, o Pibid proporciona ao graduando/bolsista a vivência da teoria na prática e a aplicação da prática dentro da teoria para, assim, poder perceber que a teoria não está distante da prática, como até então era pensado, enquanto não se vive essa realidade. Para tanto, o Pibid se encaminha como uma espécie de laboratório em que teoria e prática estejam interligadas e aconteçam de forma indissociável, e que ofereçam apoio uma à outra. Também proporciona uma experiência que a graduação não tem propiciado, pois os cursos para formação de professores são permeados “pelos conhecimentos disciplinares, conhecimentos esses produzidos geralmente numa redoma de vidro, sem nenhuma conexão com a ação profissional”, como afirma Tardif (2007, p. 23).

$\mathrm{Na}$ busca por descobrir de que forma os bolsistas do Pibid do curso de Pedagogia do Campus Avançado de Patu da Universidade Estadual do Rio Grande do Norte (CAP/Uern) vêm construindo sua formação e que experiências eles vivenciam, perguntou-se diretamente aos sujeitos escolhidos para esta pesquisa por meio de entrevista.

Ao perguntar se os sujeitos já haviam vivenciado alguma situação que gerasse aprendizados referentes à docência, ou seja, exercido a profissão de professor ou tido contato com o espaço escolar antes de entrar no Pibid, o sujeito A disse não ter "tido contato nenhum com o espaço escolar, apenas dava aulas particulares para reforço, em casa" e o sujeito $C$ respondeu que "nunca havia entrado numa sala de aula na posição de docente”. Isso se deu pelo fato de que quando eles entraram no programa, ainda estavam no 30 período do curso de Pedagogia e sequer tinham passado pela experiência do estágio, em que o graduando tem o primeiro contato com a docência no processo de formação. Essa situação é apontada pelo sujeito $D$, que disse ter tido o primeiro contato com a docência "no primeiro estágio".

O sujeito E disse já ter "participado dos estágios". Mas também comentou que foi "professora voluntária por uma semana" e que essa experiência ela resume "como um momento chocante", em que teve "muitas dificuldades". Já os sujeitos B e F responderam: 
Sim. Eu fiquei cerca de seis meses ensinando numa escola pública, numa turma de $3^{\circ}$ ano. Essa experiência foi um caos, porque era uma turma com crianças de perfis diversos, uma sala em que eu conseguia perceber que nem todos possuíam o mesmo nível, alguns não conheciam as letras do alfabeto, tinham também duas crianças especiais e um aluno fora de faixa etária. Diante dessa situação eu me desesperava e procurava todo dia na internet algum exemplo, alguma experiência de alguém que tivesse dado certo, conversava com os outros professores da escola, procurava alguma coisa que tivesse dado certo, perguntava muito aos professores, porque eu não sabia como lidar com aquela turma. Eu achava que aquela situação não era comum, uma realidade recorrente em salas de aula. Fui procurando, então, levar coisas diferentes, maneiras diferentes de ensinar. Ao final do ano eu percebi que tinha conseguido fazer alguma coisa por aquela turma, mas não o que eu queria ter feito, porque eu não tinha experiência suficiente para trabalhar com aquela turma (SUJEITO B).

Sim. Foi uma experiência traumática porque eu não tinha nenhum conhecimento teórico, não tinha nenhuma orientação acadêmica. Eu deparava com situações do dia a dia na sala de aula e não tinha como resolver as dificuldades, não tinha suporte, nem sabia que existia PCN para eu consultar, para ter uma base de como resolver as situações que eu vivia no dia a dia (SUJEITO F).

Desse modo, as falas dos três últimos sujeitos sobre suas experiências malsucedidas é explicada por Pimenta (2008, p. 20) quando diz que muitas dessas experiências são vivenciadas em "turmas de crianças e jovens turbulentos, em escolas precárias”, em que estão docentes na função de “professores a título precário" que, na maioria das vezes, "não se identificam como professores" por olharem "o ser professor e a escola do ponto de vista do ser aluno".

Muitas dessas situações se tornam traumáticas pelo fato de o professor, ainda em fase de formação, chegar às salas de aula sem os conhecimentos básicos indispensáveis ao exercício da profissão, conhecimentos esses tratados por Pimenta (2008) e Tardif (2007) como os saberes da docência. Desse modo, perguntou-se aos sujeitos o que eles entendiam por saberes docentes. Eles então responderam:

Eu acho que sejam aqueles saberes que tenham extrema importância para botar em prática na sala de aula porque sem saberes não temos norte para ir para uma sala de aula, então são indispensáveis os saberes (SUJEITO A).

Saberes docentes são os conhecimentos que o profissional adquire durante toda a sua vida desde criança, como aluno, até sua prática de muitos anos em sala de aula, que são transformados em saberes, é o que ele aprende e consegue transformar. Saberes são tudo aquilo que ele acumulou durante muito tempo de sua vida como aluno, como graduando, como acadêmico e na sua vida profissional também. Depois a experiência em sala de aula enquanto construtor do conhecimento de várias e diversas turmas (SUJEITO B). 
Eu acredito que é o início, nosso curso de Pedagogia, porque no decorrer do tempo é que a gente vai adquirindo os saberes docentes. Não existe só um nem dois saberes, existem vários e é no decorrer da carreira que vamos descobrindo (SUJEITO C).

Eu acredito que os saberes docentes partem do princípio, do que a gente começou, com os conhecimentos, toda aquela teoria, toda aquela ideologia que existe desde os primórdios. Depois vem essa prática docente que a gente está vivenciando, conhecendo o que é uma escola, o que os professores fazem dentro das novas situações, a gente vai ter a oportunidade de vivenciar uma experiência em longo prazo já como profissionais docentes em formação (SUJEITO D).

São os saberes que o professor tem que ter. O professor tem que dominar vários saberes para poder dominar o ambiente da sala de aula (SUJEITO E).

Saberes da docência eu compreendo como os saberes da teoria e da prática que o professor precisa ter. Ele precisa também ter compreendido o que é teoria e prática para poder aplicar em seu dia a dia da sala de aula (SUJEITO F).

Ao analisar as respostas obtidas, percebe-se que estas vão da subjetividade à objetividade. Em suma, as respostas se respaldam na teoria de Tardif (2007) quando define o "saber docente como um saber plural” e na de Gauthier (2006) quando ele afirma que "o conhecimento desses elementos do saber profissional docente é fundamental e pode permitir que os professores exerçam o seu ofício com mais competência”, e que para se tornar um bom profissional da área da docência é exigido "um certo número de saberes particulares que os cidadãos comuns e os trabalhadores de uma outra área não possuem".

Para que esses saberes sejam de fato construídos é preciso que os cursos de formação estejam empenhados em colaborar com essa construção dos saberes. Contudo, as vivências propostas nessa perspectiva por esses cursos são, como aponta Pimenta (2008, p. 16), “atividades de estágios distanciadas da realidade das escolas" que não dão "conta de captar as contradições presentes na prática social do educar", pois fazem parte de um "currículo formal [...] numa perspectiva burocrática" presente nesses cursos de formação.

No intuito de validar a afirmativa acima descrita, foi perguntado aos sujeitos desta pesquisa que vivências lhes foram proporcionadas pelo Pibid. Estes, por sua vez, afirmaram que:

O Pibid me proporcionou a realização de conhecer o espaço da sala de aula por um tempo longo diferente do estágio e poder ver como é a realidade de uma sala de aula, aprender como é mesmo na prática. E também a questão da moral no que se refere ao comportamento dos alunos e ser um pouco rigoroso e ter essa moral para controlar a sala (SUJEITO A).

Contato com a experiência da vida cotidiana do professor em sala de aula, o contato com o trabalho de forma colaborativa com referência ao trabalho dos docentes com o coordenador pedagógico, com a direção, ver como se dá essa relação, o contato de ver qual é a postura do professor diante das inúmeras situações incertas que a vida em sala de aula propõe como coisas 
que estavam imprevisiveis e ele procura solucionar aquilo. $O$ contato com os questionamentos e a construção da identidade dos meus colegas graduandos que passam pelas mesmas aflições que eu, questionam pontos como eu questiono, contato com pessoas que vivem e que já viveram a mesma situação que eu, o que me ajuda a construir, de certa forma, a minha carreira de forma mais segura, mais fixada, que quebra de certa forma as barreiras que o medo de um dia chegar à sala de aula sem nenhuma experiência alguma me daria. Ajudou-me muito nessa questão de dar um suporte às futuras situações que eu possa encontrar na minha carreira profissional (SUJEITO B).

Como profissional eu cresci muito, porque eu não tinha nenhuma base de como ser professor tanto na teoria quanto na prática. Como pessoa eu cresci muito por entender o lado do outro porque eu não entendia, entendia somente o que eu entendia e não outra pessoa (SUJEITO C).

Foram inúmeras, entre elas a oportunidade de conhecer a totalidade da escola, conhecimento de como conviver em coletividade, porque a gente convive entre os bolsistas, entre os professores e entre os alunos da escola e também com outros graduandos em congressos (SUJEITO D).

Proporcionou muitas vivências e experiências. Foi um momento muito bom, um momento em que pude vivenciar não só a sala de aula mas a escola como um todo, que só me foi possível conhecer quando entrei no Pibid; também me foi proporcionado o aprendizado de elaborar oficinas, de preparar coisas diferentes para os alunos (SUJEITO E).

Me proporcionou presenciar a gestão escolar, de como um gestor deve agir diante das salas de aula. Eu pude ver de perto como um gestor deve se portar diante das situações que acontecem no dia a dia da sala de aula e da escola como um todo. Pude também observar como era a sistemática de trabalho dos supervisores e coordenadores pedagógicos da escola, pois antes eu não sabia como era (SUJEITO F).

Em face do que se notifica, cabe afirmar que esses licenciandos vêm encontrando no Pibid um espaço que propicia unir os "conhecimentos dos professores" aos "seus saberes cotidianos" e assim poder renovar não só a concepção de formação que já possuem, mas também as "suas identidades, contribuições e papéis profissionais", como lembra Tardif (2007), a fim de que se tornem "professores que não se limitem a imitar outros professores, mas que se comprometam (e reflitam) na educação das crianças numa nova sociedade" e que "não sejam apenas técnicos, mas também criadores", conforme afirma Lawn (1991 apud NÓVOA, 1999, p. 26).

Assim, fica claro que o Pibid tem propiciado aos sujeitos entrevistados uma série de conhecimentos e aprendizados que até então, como ressalta Imbernón (2002, p. 64), não foram contemplados pela relação que o aluno teve "com a realidade de uma escola no período de formação", que foi somente nos períodos do estágio, descumprindo, portanto, o que o mesmo autor diz sobre as práticas nessas instituições quando aponta que estas "devem favorecer uma visão integral dessas relações", permitindo assim "que os alunos interpretem, reinterpretem e sistematizem suas experiências passada e presente" 


\section{CONCLUSÃO}

As experiências proporcionadas pelo Pibid têm garantido aos bolsistas uma visão ampla do ser professor, do seu lócus de atuação, das situações enfrentadas no dia a dia das salas de aula. Mesmo tendo tomado apenas uma amostra simbólica dos graduandos como sujeitos para esta pesquisa, percebe-se que somente a vivência teórica e prática ofertada no curso não está conseguindo construir nos futuros docentes uma formação profissional condizente com as necessidades educacionais de hoje.

Tal afirmativa é comprovada quando comparamos as falas dos entrevistados antes e depois de ingressarem no Pibid, reafirmando, portanto, o entendimento de que esse programa trouxe contribuições decisivas para a formação inicial do graduando. Mediante as respostas concedidas em entrevistas, percebese que o Pibid conseguiu empreender nos seus bolsistas uma visão real da docência, do que é ser professor de fato. O que leva à compreensão de que a experiência não se evidencia de forma tão satisfatória durante os estágios supervisionados, os quais, muitas vezes, se constituem como um dos poucos, ou talvez únicos momentos proporcionados pelas universidades para contato com o futuro campo de atuação dos pedagogos, pós-conclusão do curso.

Destarte, podemos inferir que o Pibid se configura como um importante coadjuvante na produção da formação docente, pois oportuniza vivências que levam o bolsista a aprender como definir estratégias, como tomar decisões, modificar atitudes, construir valores e até mesmo como optar ou não pela docência, pois o contato contínuo entre o graduando e seu futuro espaço de trabalho pode lhe dar a certeza de ser ou não ser esse o ofício que deseja seguir.

Concluindo, podemos então afirmar que, em meio a tantos resultados positivos, o Pibid se enquadra no conceito de política pública de formação docente, pois tem mostrado, por meio de seus bolsistas, seja nas discussões em sala de aula, seja nas discussões em congressos, que a unidade teoria/ prática concretizada pela relação universidade/escola pode ser bemsucedida e gerar experiências exitosas capazes de produzir uma formação docente mais completa e próxima do desejado para um futuro profissional da educação, que assim estará apto a contribuir para a produção de uma educação de qualidade. 


\title{
Pibid as a public policy of teacher education: discussing successful results
}

\begin{abstract}
Teacher education is made up of several steps, of which the undergraduate course is the first one. At this stage, the undergraduate student starts becoming a teacher through the theory that is present in the subjects and the practice as trainee teacher. Nevertheless, gaps are still visible in his/ her education, making it necessary for him to go through other experiences. These, in turn, are being offered by Pibid as a education program, through its unit theory/practice conceived in the interchange between university/ public school. Theoretically based on authors such as Gauthier (2006) and Tardiff (2007) among others, this article intends to present reports on how beneficiaries of Pibid experienced the relationship theory/practice in the program and its inputs for their education.
\end{abstract}

Keywords: Teacher education. Pibid. Theory/practice. 


\section{REFERÊNCIAS}

BRASIL. Ministério da Educação. Proposta de diretrizes para a formação inicial de professores da educação básica, em cursos de nível superior. Brasília: MEC, 2000.

. A Coordenação de Aperfeiçoamento de Pessoal de Nível Superior (Capes). Programa Institucional de Bolsas de Iniciação à Docência - Pibid. Projeto Institucional da Universidade do Estado do Rio Grande do Norte. Edital no 001/2011/Capes. Coord. Anadja Marilda Gomes Braz. Mossoró: UERN, 2011.

. A Coordenação de Aperfeiçoamento de Pessoal de Nível Superior (Capes). Diretoria de Educação Básica Presencial. Relatório de gestão - 2009/2011. Brasília: Capes, 2013.

CARVALHO, Marlene Araújo de. A escola e a produção de saberes. In: RIBAS, Mariná Holzmann (Org.). Formação de professores: escolas, práticas e saberes. Ponta Grossa: Ed. UEPG, 2005. p. 69-88.

ENRICONE, Délcia. Ser professor. 6. ed. atual. Porto Alegre: EDIPUCRS, 2008.

GAUTHIER, Clermont. Por uma teoria da pedagogia: pesquisas contemporâneas sobre o saber docente. 2. ed. ljuí: Ed. Unijuí, 2006.

IMBERNÓN, Francisco. Formação docente e profissional: formar-se para a mudança e a incerteza. 3. ed. São Paulo: Cortez, 2002.

NÓVOA, Antônio (Org.). Profissão professor. 2. ed. Porto: Porto Editora, 1999.

PIMENTA, Selma Garrido. Formação de professores: identidade e saberes da docência. In: Saberes pedagógicos e atividade docente. São Paulo: Cortez, 2008. p. 15-32.

RAMALHO, Betania Leite. Formar o professor, profissionalizar o ensino. Porto Alegre: Sulina, 2003.

ROMANOWSKI, Joana Paulin. Formação e profissionalização docente. 3. ed. Curitiba: Ibepex, 2007.

TARDIF, Maurice. Saberes docentes e formação profissional. 8. ed. Petrópolis: Vozes, 2007.

RECEBIDO: Abril de 2015.

APROVADO: Maio de 2015. 